\title{
Preparation and Some Properties of a Nanocomposite of Polyacrylonitrile with Acetylene Black
}

\author{
Arjun MAITY and Mukul BISWAS ${ }^{\dagger}$ \\ Department of Chemistry, Presidency College, Calcutta-73, India
}

(Received April 15, 2004; Accepted July 12, 2004; Published October 15, 2004)

\begin{abstract}
Conducting nanocomposites of polyacrylonitrile (PAN) with acetylene black (AB) were prepared via $\mathrm{K}_{2} \mathrm{CrO}_{4}-\mathrm{NaAsO}_{2}$ initiated redox polymerization of acrylonitrile in presence of $\mathrm{AB}$ suspension in aqueous-methanol medium at $60^{\circ} \mathrm{C}$. Prolonged extraction of PAN-AB composite by DMF failed to extract the loaded polyacrylonitrile completely from the acetylene black, as confirmed by FT IR studies. SEM analyses revealed the formation of agglomerates of particles of nonuniform sizes and shapes. TEM analysis indicated that average particle diameters of the PAN$\mathrm{AB}$ composite were in the range of $120-250 \mathrm{~nm}$. Thermal stability of the PAN-AB composite was appreciably improved relative to that for the unmodified base polymer. The dc conductivity of the PAN-AB composite was in the range of $10^{-4}-10^{-2} \mathrm{~S} / \mathrm{cm}$ depending on the amount of $\mathrm{AB}$ in the $\mathrm{PAN}-\mathrm{AB}$ composite, a value remarkably improved relative to that of the PAN homopolymer $\left(>10^{-11} \mathrm{~S} / \mathrm{cm}\right)$. [DOI 10.1295/polymj.36.812]

KEY WORDS Polyacrylonitrile / Acetylene Black / $\mathrm{K}_{2} \mathrm{CrO}_{4}-\mathrm{NaAsO}_{2}$ Redox System / Thermal Stability / Conductivity /
\end{abstract}

Considerable research interest has been shown lately in the modification of fundamental polymers like polyacrylonitrile (PAN), polymethylmethacrylate (PMMA), polystyrene (PS), etc. with a view to enhancing the scope of practical application of these materials. A widely investigated method in this direction is the preparation of conducting polymer blends and composites of the speciality conducting polymers such as polyaniline (PANI), polypyrrole (PPY), and polythiophene (PTP) with conventional polymers like PAN, PMMA, PS, etc. Several workers ${ }^{1,2}$ reported on the preparation of conducting polymeric blends/composites of PPY-PVc and PPY-PMMA via electrochemical and oxidative polymerization methods respectively. Stanke et al. ${ }^{3}$ synthesized a conducting graft copolymer film of PMMA and PPY by oxidative polymerization of pyrrole with $\mathrm{FeCl}_{3}$. Ruckenstein ${ }^{4,5}$ described preparation and evaluation of polyaniline/ poly(alkylmethacrylate) and polypyrrole/poly(alkylmethacrylate) composites with high electrical conductivity $(6 \mathrm{~S} / \mathrm{cm})$.

In an alternative process, blending polymers with conducting fillers, such as natural graphite flake, carbon black, and powders, to prepare electrically conducting composites has been extensively investigated in the past few decades. In this context, Chen et al. ${ }^{6}$ prepared conducting PMMA/graphite nanosheet composites via in-situ polymerization of methylmethacrylate (MMA) by benzoyl peroxide in aqueous alcohol solution in presence of expanded graphite (EG). We recently reported $^{7}$ that acetylene black $(\mathrm{AB})$ - the purest form of highly conducting carbon black, was capable of initiating the polymerization of $N$-vinylcarbazole. Interestingly, this system led to the simultaneous formation of a PNVC-AB composite with a conductivity in the order of $10^{-2} \mathrm{~S} / \mathrm{cm}$. Earlier, Japanese groups $^{8-13}$ reported the polymerization of vinyl monomers like styrene, $\alpha$-methystyrene, isobutyl vinyl ether (IBVE), $N$-vinyl-2-pyrrolidone (NVP) in the presence of carbon black (CB) and external catalyst vis-a-vis formation of graft composites in the systems. Biswas et al. ${ }^{14-17}$ also explored the initiation of the polymerization of the NVC by Orient black (N220), Vulcan XC-72, etc. without any external oxidant.

In this background, we wish to describe in this article a novel procedure for the preparation of a highly conducting PAN-AB composite via $\mathrm{K}_{2} \mathrm{CrO}_{4}-\mathrm{NaAsO}_{2}$ initiated redox polymerization of acrylonitrile in aqueous alcoholic medium and also report some relevant properties of the PAN-AB composite.

\section{EXPERIMENTAL}

\section{Materials and Methods}

Acrylonitrile (Aldrich, USA) was freed from inhibitor by successive washings with dilute sodium carbonate solution, dilute sulphuric acid and finally with distilled water. It was kept over-night over calcium chloride and distilled in an all glass apparatus. The fraction boiling at $77-78^{\circ} \mathrm{C}$ was collected and stored carefully. Acetylene black (SENCO India, Chenai, India) was preheated by heating at $120^{\circ} \mathrm{C}$ for $2 \mathrm{~h}$ in vacuum prior to use. Potassium chromate (Riedel, Germany) and sodium arsenite (Riedel) were used as

${ }^{\dagger}$ To whom correspondence should be addressed (Tel: +91-33-2521-3556; Fax: +91-33-2234-6075; E-mail: mukul_biswas@vsnl.net). 
the oxidant and the reductant respectively. All other solvents were of analytical grade and were freshly distilled before used.

\section{Polymerization of Acrylonitrile with $\mathrm{K}_{2} \mathrm{CrO}_{4}-\mathrm{NaAsO}_{2}$ Redox System}

$\mathrm{K}_{2} \mathrm{CrO}_{4}(0.2 \mathrm{~g})$ was dissolved in $30 \mathrm{~mL}$ of watermethanol mixture $(3 \mathrm{~mL} \mathrm{MeOH})$ in a Pyrex flask to which $1.5 \mathrm{~mL}$ of acrylonitrile was injected. The system was kept under stirring at room temperature under $\mathrm{N}_{2}$ atmosphere for $10 \mathrm{~min}$ and thereafter, $0.3 \mathrm{~g}$ of $\mathrm{NaAsO}_{2}$ was dissolved into this solution. Then the total system was kept at $60^{\circ} \mathrm{C}$ for $6 \mathrm{~h}$. Thereafter, the white polymer was centrifuged, washed in succession with distilled water, methanol, and acetone and finally dried in vacuum for $12 \mathrm{~h}$.

\section{Preparation of PAN-AB Nanocomposite}

In a Pyrex flask, $0.02-5 \mathrm{~g}$ of $\mathrm{AB}$ was added to $30 \mathrm{~mL}$ of water-methanol mixture (3 mL methanol) under sonication for $1 \mathrm{~h}$ to make a suspension of $\mathrm{AB}$ in which $0.2 \mathrm{~g}$ of $\mathrm{K}_{2} \mathrm{CrO}_{4}$ was dissolved and $1.5 \mathrm{~mL}$ of acrylonitrile was injected. Thereafter, $0.3 \mathrm{~g}$ of $\mathrm{NaAsO}_{2}$ was added to it. The system was kept at $60^{\circ} \mathrm{C}$ with stirring for $6 \mathrm{~h}$ under $\mathrm{N}_{2}$ atmosphere. The total black mass was washed in succession with distilled water, methanol and acetone and finally dried in vacuum for $12 \mathrm{~h}$.

The total PAN-AB composite thus obtained was extracted with DMF through continuous refluxing for one week at $50{ }^{\circ} \mathrm{C}$. The total separated mass was centrifuged, a process repeated at least four times until the extract did not yield any precipitate with methanol due to any residual surface adsorbed PAN. This residue was finally dried at $60^{\circ} \mathrm{C}$ for $12 \mathrm{~h}$ under vacuum. After various physicochemical characterizations, the composite was confirmed to contain PAN along with $\mathrm{AB}$.

\section{Characterization and Property Evaluation}

Intrinsic viscosity of PAN homopolymer was determined with an Oswald viscometer in DMF solution at $25^{\circ} \mathrm{C}$ and molecular weight was calculated using the Ueberreiter-Springer equation $[\eta]=1.66 \times 10^{-5} \times$ $M^{0.81}{ }^{18}$ The FT IR spectrum of PAN-AB composite was taken on a JASCO-410 instrument in pressed $\mathrm{KBr}$ pellet. Dispersion of PAN-AB composite in 2propanol was microsprayed on a mica substrate. The sample was sputter coated with gold layer and a Hitachi S-415 A scanning electron micrograph was used to take the micrograph. Thermogravimetric analyses were performed on a Shimadzu DT-40 instrument. Direct current (dc) conductivity measurements were made on pressed pellets with a silver coating, using the conventional four-probe technique.

\section{RESULTS AND DISCUSSION}

\section{General Features of Composite Formation}

Table I presents some results on the polymerization of AN vis-a-vis composite formation of polyacrylonitrile with acetylene black. 85\% PAN homopolymer was formed when the polymerization was conducted under conditions summarized in Table I. Entries 1-8 indicate that the percent conversion of PAN homopolymer decreased with increasing weight of $\mathrm{AB}$ at fixed amount of redox system and monomer in the initial feed. A notable feature was that after prolonged extraction of $\mathrm{PAN}-\mathrm{AB}$ composites with $\mathrm{DMF}$ at $60^{\circ} \mathrm{C}$, some residual amount of PAN (last column, Table I) was found to be present in the PAN-AB composite. This could be due to fact that PAN homo-

Table I. Some typical data on composite formation ${ }^{\mathrm{a}}$ of polyacrylonitrile with $\mathrm{AB}$

\begin{tabular}{cccccc}
\hline \multirow{2}{*}{$\begin{array}{c}\text { Entry } \\
\text { No }\end{array}$} & $\begin{array}{c}\text { Weight } \\
\text { of AB } \\
(\mathrm{g})\end{array}$ & $\begin{array}{c}\text { Weight of } \\
\text { composite }(\mathrm{g})\end{array}$ & $\begin{array}{c}\text { \% polymer } \\
\text { formed }\end{array}$ & $\begin{array}{c}\text { \% of polymer } \\
\text { grafted per g of } \\
\text { composite }\end{array}$ \\
\cline { 3 - 4 } & & 0.73 & 0.09 & 57 & 78 \\
\hline 1 & 0.02 & 0.63 & 0.14 & 50 & 78 \\
3 & 0.03 & 0.56 & 0.15 & 45 & 73 \\
4 & 0.04 & 0.53 & 0.18 & 40 & 72 \\
5 & 0.05 & 0.50 & 0.25 & 33 & 60 \\
6 & 0.10 & 0.45 & 0.36 & 21 & 34 \\
7 & 0.20 & 0.52 & 0.365 & 18 & 35 \\
8 & 0.30 & 0.73 & 0.70 & 19 & 28 \\
\hline
\end{tabular}

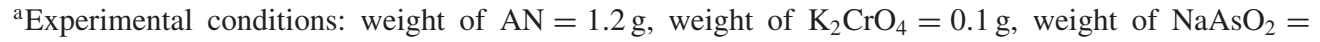
$0.3 \mathrm{~g}$, total volume $=30 \mathrm{~mL}$ ( water $=27 \mathrm{~mL}$ and $\mathrm{MeOH}=3 \mathrm{~mL}$ ), temperature $=60^{\circ} \mathrm{C}$, time of polymerization $=6 \mathrm{~h} ;{ }^{\mathrm{b}} \%$ polymer formed in the control experiment (without $\mathrm{AB}$; using same experimental conditions mentioned above) was $85 \% ; \%$ polymer in the composite $=[($ column $3-$ column 2$) / 1.2] \times$ $100{ }^{\mathrm{c}} \%$ grafting $=[($ column $4-$ column 2$) /$ column 4$] \times 100$ 
polymer was grafted on the acetylene black surface.

Biswas and Maity recently reported ${ }^{19}$ that the polymerization of acrylonitrile by $\mathrm{K}_{2} \mathrm{CrO}_{4}-\mathrm{NaAsO}_{2}$ redox system occurred via free radical pathway as follows:

$$
\begin{array}{cc}
\mathrm{NaAsO}_{2}+\mathrm{H}_{2} \mathrm{O}=\mathrm{NaH}_{2} \mathrm{AsO}_{2} & (\text { ref 20) } \\
\mathrm{H}_{2} \mathrm{AsO}_{3}{ }^{-}+\mathrm{Cr}^{6+}=\mathrm{H}_{2} \mathrm{AsO}_{3}{ }^{\bullet}+\mathrm{Cr}^{5+} & (\text { ref 21) }
\end{array}
$$

Initiation

$$
\begin{aligned}
& \mathrm{H}_{2} \mathrm{AsO}_{3}{ }^{\bullet}+\mathrm{CH}_{2}=\mathrm{CH}-\mathrm{CN} \\
& \quad \longrightarrow \mathrm{H}_{2} \mathrm{AsO}_{3}-\mathrm{CH}_{2}-\mathrm{C}^{\bullet} \mathrm{H}-\mathrm{CN}
\end{aligned}
$$

Propagation

$$
\begin{aligned}
& \mathrm{H}_{2} \mathrm{AsO}_{3}-\mathrm{CH}_{2}-\mathrm{C}^{\bullet} \mathrm{H}-\mathrm{CN}+n \mathrm{CH}_{2}=\mathrm{CH}-\mathrm{CN} \\
& \quad \longrightarrow \mathrm{H}_{2} \mathrm{AsO}_{3}-\left(\mathrm{CH}_{2}-\mathrm{CH}(\mathrm{CN})\right)_{n}-\mathrm{CH}_{2}-\mathrm{C}^{\bullet} \mathrm{H}-\mathrm{CN}
\end{aligned}
$$

It is well established ${ }^{8-17}$ by ESR studies that carbon black systems have unpaired electrons. Tsubokawa et $a .^{22,23}$ reported on the grafting of some vinyl monomers on $\mathrm{CB}$ in the presence of free radical initiators. Relevantly, Biswas et al. ${ }^{14,16}$ found that simultaneous precipitation of PNVC by methanol addition to the polymerizing solution ( $\mathrm{NVC}+\mathrm{CB}+$ benzene) was effective in producing a $\mathrm{PNVC}-\mathrm{CB}$ graft composite. In this background, we believe that the proposed grafting between growing PAN moieties and AB could be via free radical coupling as the following equation.

$$
\begin{aligned}
& \mathrm{H}_{2} \mathrm{AsO}_{3}-\left(\mathrm{CH}_{2}-\mathrm{CH}(\mathrm{CN})\right)_{n}-\mathrm{CH}_{2}-\mathrm{C}^{\bullet} \mathrm{H}-\mathrm{CN}+\mathrm{AB}{ }^{\bullet} \\
& \quad \longrightarrow \mathrm{H}_{2} \mathrm{AsO}_{3}-\left(\mathrm{CH}_{2}-\mathrm{CH}(\mathrm{CN})\right)_{n}-\mathrm{CH}_{2}-\mathrm{CH}(\mathrm{CN})-\mathrm{AB}
\end{aligned}
$$

One of the reviewers pointed out that free radicals in CB are unable to trap radicals. In this context, we wish to submit that we observed ${ }^{7,14-17}$ direct initiation of NVC polymerization by $\mathrm{CB}, \mathrm{AB}$ and fullerene without any external initiators via electron transfer reaction between nitrogen lone pair of NVC and free electron in $\mathrm{CB} / \mathrm{AB} /$ fullerene. In the latter system, our contention was endorsed by Chen et al. ${ }^{24}$ who obtained ESR evidence for the electron transfer reaction. Secondly, in this particular system we failed to obtain any $\mathrm{PAN}-\mathrm{AB}$ graft composite from preformed PAN and $\mathrm{AB}$ suspension. The $\mathrm{PAN}-\mathrm{AB}$ graft composite was only obtained during in-situ polymerization of $\mathrm{AN}$ in presence of $\mathrm{AB}$ and redox system.

\section{FT IR Absorption Characteristics of PAN-AB Com- posite}

Table II summarizes the FT IR peaks for the PANbased composites along with their probable assignments. The presence of PAN in the PAN-AB composite recovered after repeated extraction with DMF was supported by the appearance of FT IR peaks $\left(\mathrm{cm}^{-1}\right)$ at 2924, 2260 and 1460 which matched with the reported FT IR spectra for PAN. ${ }^{25-27}$
Table II. FT IR absorption characteristics of PANhomopolymer and of PAN-AB composite

\begin{tabular}{ccc}
\hline PAN & $\begin{array}{r}\text { Absorption of PAN-AB } \\
\text { composite }\left(\mathrm{cm}^{-1}\right)\end{array}$ & \multicolumn{1}{c}{ Assignments } \\
\hline 2939 & 2924 & $\mathrm{C}-\mathrm{H}$ stretching vibration \\
2245 & 2260 & $\mathrm{C} \equiv \mathrm{N}$ stretching vibration \\
1454 & 1460 & $\mathrm{C}-\mathrm{H}$ bending vibration \\
\hline
\end{tabular}
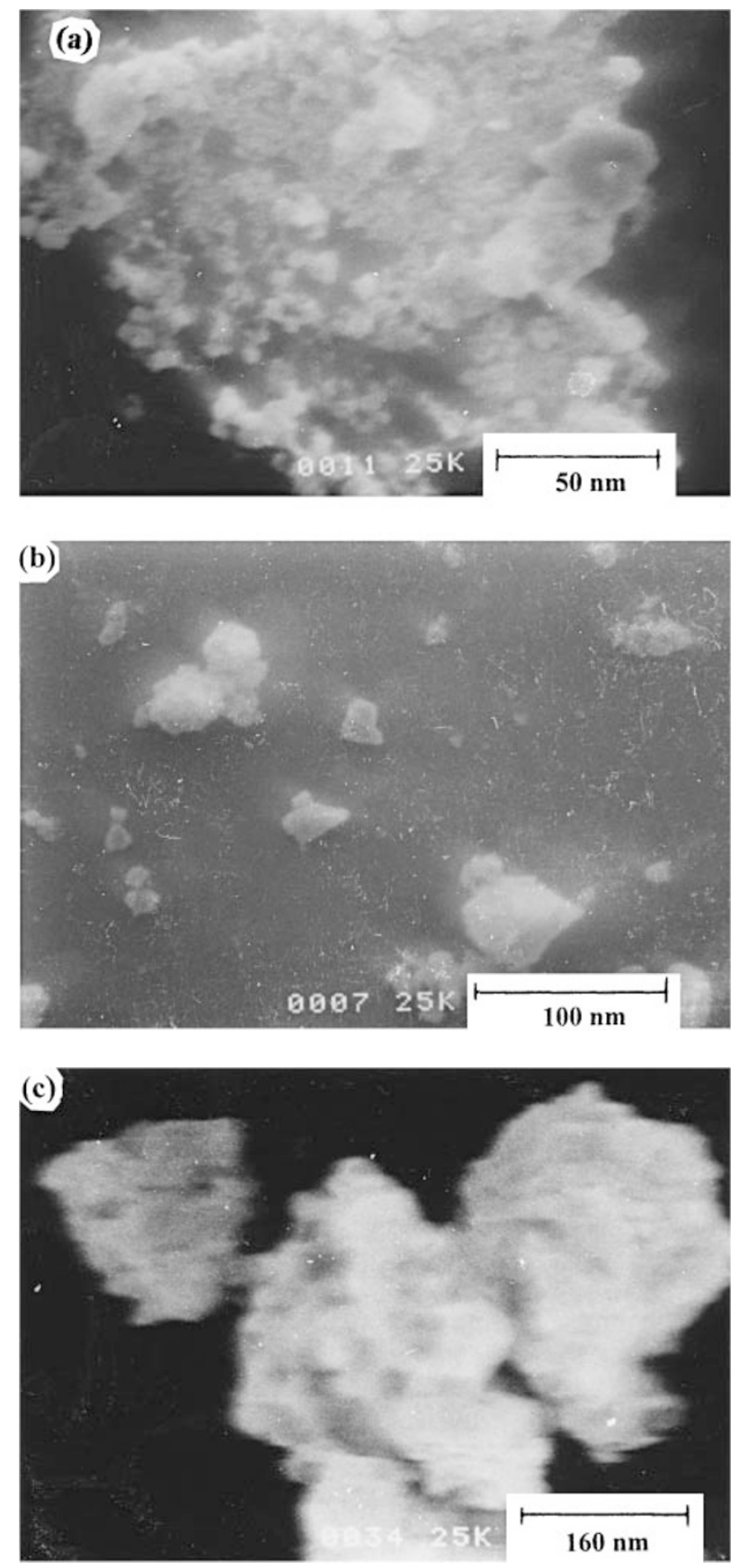

Figure 1. Scanning electron micrographs of (a) AB (b) PAN homopolymer (c) PAN-AB composite (entry 8; Table I).

\section{Scanning Electron Micrographic Characterization}

The SEM morphology for AB (Figure 1a) showed presence of small nearly spherical $A B$ particles with 
the tendency to form larger lumps $(40 \mathrm{~nm})$ randomly distributed on the surface. The morphology for PAN homopolymer (Figure 1b) was essentially indicative of the formation of lumpy aggregates of mixed sizes ranging from $10-70 \mathrm{~nm}$ with definite pattern. In contrast, SEM photograph of the PAN-AB composite suggested the formation of lumpy agglomerates of much larger particles with nonuniform sizes (130$300 \mathrm{~nm}$ ) and shapes. The formation of such microaggrgates could result through cementation of nanosized $\mathrm{AB}$ particles with the precipitating PAN homopolymer - a situation similar to the scenario described by Armes and Maeda ${ }^{28}$ in their PPY-metal oxide nanocomposite systems where the nanocomposites were considered to be made up of microaggregates "glued" together by the precipitating PPY component. Such morphology was believed ${ }^{29}$ to be the reason for the manifestation of attractive conductivity value. In the light of this concept the high conductivity of the PAN-AB composite is consistent with the compact interparticle morphology in $\mathrm{PAN}-\mathrm{AB}$ composite.

\section{Transmission Electron Micrographic Characteriza- tion}

Transmission electron micrograph of $\mathrm{PAN}-\mathrm{AB}$ composite presented in Figure 2, revealed the appearance of spherical particles with sizes varying between $120-250 \mathrm{~nm}$. The observed presence of dark globular particles along with the lighter once is reminiscent of the TEM micrograph realized with PPY-metal oxide and PANI-metal oxide nanocomposite systems reported earlier. ${ }^{28-30}$

\section{Thermal Stability Characteristics}

Percent weight retained versus temperature studies (Figure 3) for $\mathrm{AB}, \mathrm{PAN}-\mathrm{AB}$ composite and $\mathrm{PAN}$

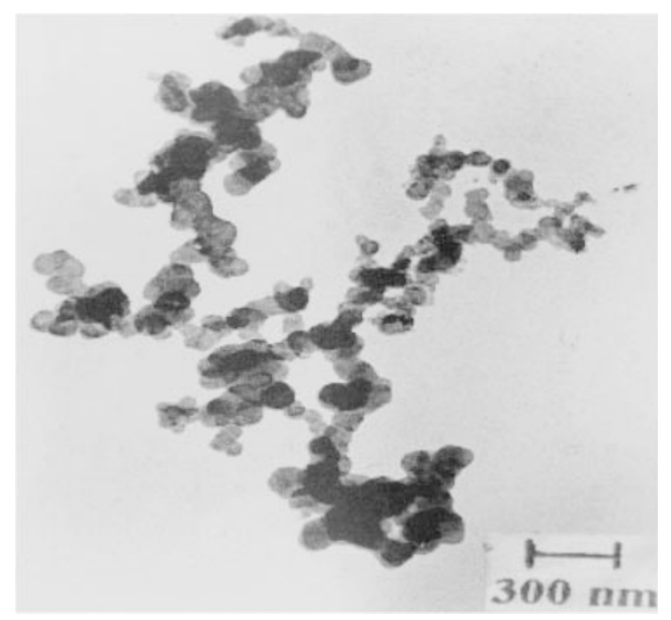

Figure 2. Transmission electron micrograph of PAN-AB composite (entry 8; Table I).

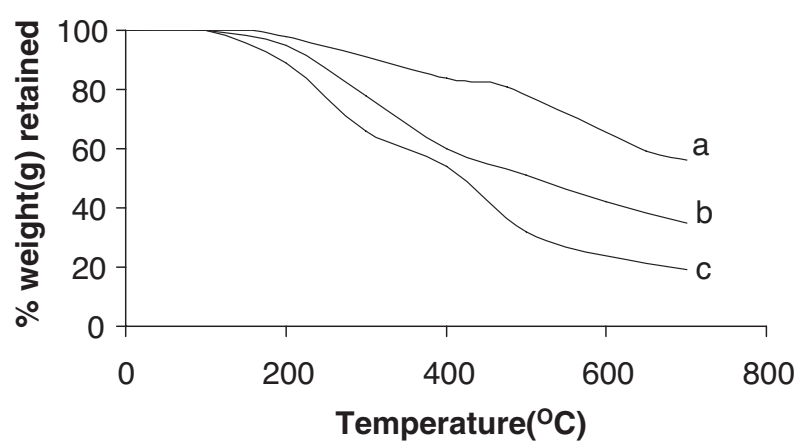

Figure 3. TGA of (a) $\mathrm{AB}$ (b) PAN-AB composite (entry 8; Table I) (c) PAN-homopolymer.

homopolymer revealed the following trend in the order of thermogravimetric stability: (a) initial decomposition temperature varied as $\mathrm{AB}>\mathrm{PAN}-\mathrm{AB}$ $>$ PAN (b) temperature for $50 \%$ decomposition varied as $\mathrm{AB}>\mathrm{PAN}-\mathrm{AB}>\mathrm{PAN}$ (c) limiting decomposition temperature varied as $\mathrm{AB}>\mathrm{PAN}-\mathrm{AB}$ $>$ PAN. The intermediate stability of PAN-AB composite could manifest from the incorporation of less stable PAN moieties, in more stable $\mathrm{AB}$ in the PAN-AB composite. A similar trend was also reported for a variety of polymer-metal oxide nanocomposite systems. ${ }^{31-33}$

The DTA scan for the PAN-AB composite revealed exothermic peaks at 335,518 and $550^{\circ} \mathrm{C}$ respectively. The peak at $550^{\circ} \mathrm{C}$ did not manifest in the TGA of PAN homopolymer. ${ }^{19}$ Probably this peak resulted from the oxidative degradation of various functional groups $(-\mathrm{OH},-\mathrm{COOH},>\mathrm{C}=\mathrm{O},-\mathrm{CHO} \text {, etc. })^{10,12,34}$ known to be present in various types of carbon black.

\section{Conductivity Characteristics}

The dc conductivity value of PAN homopolymer was in the order of $10^{-11} \mathrm{~S} / \mathrm{cm} .{ }^{19}$ Interestingly, conductivity of the PAN-AB composite increased with increasing weight per centage of $\mathrm{AB}$ in the composite (Table III). However, at 3\% AB content, the conductivity was increased $\sim 10^{7}$ fold compared to that of PAN homopolymer while the value progressively increased by $10^{2}$ fold corresponding to a 10 fold increase in the per cent of $\mathrm{AB}$ in the $\mathrm{PAN}-\mathrm{AB}$ compo-

Table III. Conductivity values of PAN-AB composites

\begin{tabular}{cccc}
\hline $\begin{array}{c}\text { Entry } \\
\text { No }\end{array}$ & Materials & $\begin{array}{c}\text { \% of AB content } \\
\text { in the composite }\end{array}$ & $\begin{array}{c}\text { Conductivity } \\
(\mathrm{S} / \mathrm{cm})\end{array}$ \\
\hline 1 & PAN homopolymer $^{\mathrm{a}}$ & 0 & $>10^{-11}$ \\
2 & PAN-AB composite & 3 & $2.1 \times 10^{-4}$ \\
3 & PAN-AB composite & 6 & $1.9 \times 10^{-3}$ \\
4 & PAN-AB composite & 10 & $2.5 \times 10^{-2}$ \\
5 & PAN-AB composite & 31 & $8 \times 10^{-2}$ \\
\hline
\end{tabular}

${ }^{\mathrm{a}}$ See ref 19. 
site (entries 3 and 5, Table III). This feature is quite consistent with the reported conductivity enhancement of polymers blended with conductive fillers. ${ }^{6}$

\section{CONCLUSIONS}

Conducting nanocomposites of $\mathrm{PAN}-\mathrm{AB}$ were prepared via $\mathrm{K}_{2} \mathrm{CrO}_{4}-\mathrm{NaAsO}_{2}$ redox initiated polymerization of $\mathrm{AN}$ in presence of $\mathrm{AB}$ in aqueous-alcohol dispersions. The conductivity of the PAN-AB composite increased by $10^{7}$ to $10^{9}$ fold relative to that of PAN homopolymer corresponding to $\mathrm{AB}$ loading of $3 \%$ to $31 \%$ respectively.

Acknowledgment. We thank the authorities of Presidency College, Calcutta, India, for facilities, to the Director of Central Glass and Ceramic Research Institute, Calcutta, India, for helpful discussions and measurements of conductivity, to Mr. P. Ray, Saha Institute of Nuclear Physics, Calcutta, India, for TEM analyses.

\section{REFERENCES}

1. M. Morita, I. Hashia, and M. Nishimura, J. Appl. Polym. Sci., 36, 1639 (1988).

2. M. A. De Paoli, R. J. Waltman, A. F. Diaz, and J. J. Bargon, J. Poly. Sci., Polym. Chem. Ed., 23, 1685 (1985).

3. D. Stanke, M. L. Hallensleben, and L. Toppare, Synth. Met., 55-57, 1108 (1993).

4. S. Yang and E. Rukenstein, Synth. Met., 59, 1 (1993).

5. E. Rukenstein and S. Yang, Polymer, 34, 4655 (1993).

6. G. Chen, W. Weng, D. Wu, and C. Wu, Eur. Polym. J., 39, 2329 (2003).

7. N. Ballav, A. Maity, and M. Biswas, Mater. Chem. Phys., 87, 120 (2004).

8. K. Ohkita, N. Tsubokawa, E. Saitoh, M. Noda, and N. Takashina, Carbon, 13, 443 (1975).

9. N. Tsubokawa, J. Polym. Sci., Polym. Lett. Ed., 18, 461 (1980).

10. K. Ohkita, M. Uchiyama, and H. Nishioka, Carbon, 16, 195 (1978).
11. K. Ohkita, N. Tsubokawa, M. Noda, and M. Uchiyama, Carbon, 15, 195 (1977).

12. N. Tsubokawa, N. Takeda, and K. Kudoh, Carbon, 18, 163 (1980).

13. N. Tsubokawa, N. Takeda, and A. Kanamaru, J. Polym. Sci., Polym. Chem. Ed., 18, 625 (1980).

14. M. Biswas and S. A. Haque, J. Polym. Sci., Polym. Chem. Ed., 21, 1861 (1983).

15. M. Biswas and S. A. Haque, Polym. Commun., 26, 122 (1985).

16. M. Biswas and A. Roy, Polymer, 34, 2903 (1993).

17. M. Biswas and A. Roy, Polymer, 35, 4471 (1994).

18. K. Ueberreiter and J. Z. Springer, Z. Phys. Chem., 36, 229 (1963).

19. A. Maity and M. Biswas, Polym. J., 35, 993 (2003).

20. P. L. Smedley and D. G. Kinniburgh, Appl. Geochem., 17, 517 (2002).

21. C. H. Bamford, W. G. Barb, A. D. Jenkins, and P. F. Onyon, "The Kinetics of Vinyl Polymerization by Radical Mechanism," London, U.K, 1958, p 223, and reference cited therein.

22. K. Ohkita, M. Uchiyama, and E. Saittoh, Carbon, 16, 41 (1978).

23. N. Tsubokawa, Y. Nagano, and Y. Sone, Polym. Bull., 10, 404 (1983).

24. Y. Chen, J. Wang, J. Shen, R. Cai, and Z. Huang, J. Polym. Sci., Part A: Polym. Chem., 37, 3745 (1999).

25. Y. Sugahara, S. Satokawa, K. Kuroda, and C. Kato, Clay Clay Miner., 36, 343 (1988).

26. N. V. Bhat and E. Sundaresan, J. Appl. Polym. Sci., 42, 1615 (1991).

27. J. G. Bokria and S. Schlick, Polymer, 43, 3239 (2002).

28. S. Maeda and S. P. Armes, Chem. Mater., 7, 171 (1995).

29. S. P. Armes, S. Gottesfeld, J. G. Berry, F. Garzon, and S. F. Agnew, Polymer, 32, 2325 (1992).

30. S. Maeda, M. Gill, and S. P. Armes, Langmuir, 11, 1899 (1995).

31. A. Maity and M. Biswas, J. Appl. Polym. Sci., 88, 2233 (2003).

32. S. S. Ray and M. Biswas, Synth. Met., 99, 105 (1999).

33. N. Ballav and M. Biswas, Polym. Int., 52, 179 (2003).

34. M. Biswas and S. A. Haque, Angew. Macromol. Chem., 129, 43 (1985). 